\title{
Understanding the Link Between Social Skills and Phone Use
}

\author{
Kennedy Ralph ${ }^{1}$ and Aurora Ramos Nunez ${ }^{1 \#}$ \\ ${ }^{1}$ College of Coastal Georgia, Brunswick, GA, USA \\ \#Advisor
}

ABSTRACT

Smartphones took the world by storm in the 2000s. Over the years, smartphones have become vital in everyday life. Each generation responds to technology differently. The younger generation is much more involved with smartphones as well as technology as a whole. Thus, spending too much time on a smartphone could be related to individual's wellbeing. The purpose of the present study is to measure Emotional Intelligence (EI), mindfulness, and social competence among different age cohorts and see if there are differences in phone use. Our hypothesis is that participants who score higher on EI, Social Skills, and Mindfulness will score lower on the Problematic Phone Usage Scale. Younger adults will score lower on EI, Social Skills, and Mindfulness and higher on Problematic Phone Usage than middle aged and older adults. We ran correlational analyses among the factors EI, mindfulness, social competence, and problematic phone usage and an ex-post facto comparison between the four cohorts with ages ranging 18-30 ( $n=105), 31-40$ years old $(n=30), 41-50(n=30)$, and 51 and older $(n=21)$. Survey questions included the Trait Emotional Intelligence Questionnaire- Short Form (TEIQ-SF), Kentucky Inventory of Mindfulness Skills, Social Competence, and Problematic Phone Usage Scale. Data showed that as age increased phone use decreased. EI, mindfulness, and social competence scores for younger adults were much lower than for middle aged and older adults while younger adults had a significantly larger problematic phone use than middle aged.

\section{The Social Impact of Smart Phone Utilization}

Smartphones have become increasingly popular over the past few decades. Pew Research Center (2019) indicates that $96 \%$ of Americans have a cellphone and $81 \%$ have a smartphone. Of those people, the largest percentage that has a smartphone is between the ages of 18-29. While older adults have cellphones, it is evident that the younger generation is more involved with online communication. Excessive amounts of time spent on a smartphone takes away from in person communication and interaction, self-reflection, and emotional processing. Based off of previous research, it is known that online communication can negatively affect an individual's ability to self-regulate, leading to anxiety, depression, and a lower self-esteem. (Alhassan et al., 2018; Arrivillaga et al., 2020; Bian \& Leung, 2015; Bianchi \& Phillips, 2005; Chang, 2018; Favotto et al., 2017; Kaiser, 2018; Kaiser Family Foundation, 2010; Kaypakli et al., 2020; Kunnanatt, 2004; Mayer et al., 2008; Munderia and Singh, 2019; Pew Research Center, 2019; Scott et al., 2016; Sural et al., 2019).

\section{Computer Mediated Communication}

Smartphones are a form of communication among many individuals across the globe. This form of communication is considered computer mediated communication (CMC) and is a way of communicating online through electronic devices (Kaiser, 2018). Communication online can include social media, texting, phone calls, and facetime. Overuse of CMC has been found to result in negative emotions and social relations with others (Favotto et al., 2017). Previous 
studies suggest that mental and emotional state are impaired by overuse of the internet (Bian and Leug, 2014; Bianchi and Phillips, 2005; Scott et al., 2016). Bianchi and Phillips (2005) used a Mobile Phone Use Survey that consisted of 27 questions relating to how people feel about mobile phones and how often they use them. Through their research, Bianchi and Phillips (2005) found that individuals use their smartphones to escape problems in their everyday lives. They noticed that this form of escapism failed to be controlled in younger individuals; therefore, they experience a greater impulse towards technology. These researchers propose that problematic phone use could result in impulse control or depression.

$\mathrm{CMC}$ is beneficial because it allows us to always stay connected to others. Always being connected can blur the line between the division of keeping home at home and work at work and this disconnect can be emotionally stressful (Scott et al., 2016). As a result, "connectivity, accessibility, and information overload can contribute to a variety of mental health problems including stress, anxiety, and depression" (Scott et al., 2016 p. 605). In the review by Scott et al. (2016), the researchers listed ways that information overload can impact a person. This includes a decrease in emotional connection between individuals, lower self-esteem, and disintegration of empathy. This statement is supported by Bian and Leung's (2014) research study on psychological attributes and smartphone patterns that can predict smartphone addiction symptoms, that the higher levels of smartphone addiction were correlated with depression, low self-esteem, and loneliness.

The effects that information overload above mentioned could be a result of the amount of time an individual spends on their phone. Kaiser Family Foundation (2010) conducted a national stratified survey study on youth between the ages of 8 and 18 with 2,002 participants. The researchers found that youth spent an average of $71 / 2$ hours a day on media which leaves little time for self-reflection. In the study conducted by Kaiser Family Foundation, (2010) the researchers grouped youth into three groups, heavy users of media, moderate users, and light users. Those who were in the heavy category reported that they consumed more than 16 hours of media content throughout the day. Kaiser Family Foundation (2010) found that those who were in the heavy group reported poorer grades (C or below) and often felt sad. These researchers reported that those who score lower on contentedness spent more time on social media. Alhassan et al. (2018) found that younger individuals were more likely to be addicted to smartphones than older individuals due to accessibility to technology. These researchers study reported a positive correlation between smartphone addiction and depression and states that this addiction is related to a lack of self-control rather than possession of the smartphone itself.

\section{Emotional Intelligence}

Emotional intelligence (EI) is the way one regulates and manages their own emotions as well as the way an individual perceives and interprets other's emotions (Goleman, 1995). The connection between smartphones and our everyday lives could potentially result in a decline in human emotions and connectivity among one another, therefore hindering EI. When using CMC as a form of communication, an individual might be missing the art of eye contact as well as tone of voice and body language. These are forms of communication that play a role in understanding human emotion and strengthening our emotional intelligence. When using CMC, we could potentially be losing that humanistic communication and hindering the ability to be able to interpret other's emotions because of the lack of social skills that are acquired through in-person communication. Scott et al. (2016) suggests that Internet overload can impact our everyday lives by stress, decrease in our emotional connection with others, a need for instant gratification, lack of attention, and erosion of empathy.

In-person communication helps strengthen our ability to understand emotions of others; however, being connected online can decrease the time we spend communicating in person. In a theoretical paper, Mayer et al. (2008) proposed four branches of emotional intelligence including: "(a) perceived emotions in oneself and others accurately, (b) use emotions to facilitate thinking, (c) understand emotions, emotional language, and the signals conveyed by emotions, and (d) manage emotions as to attain specific goals" (p.507). Arrivillaga et al. (2020) conducted a research study on adolescents' problematic phone usage in relation to suicide ideation and if an increase in emotional 
intelligence could make a difference. These researchers found that those who had a lower smartphone use had a higher emotional intelligence. They suggest that EI might be helpful in reducing negative smartphone use symptoms. Similarly, Kaypakli's et al. (2020) research study on technological addictions in adolescents with ADHD, found that those who have a lower EI seem to suffer more addictive smartphone symptoms than those with a higher EI. These researchers state that individuals who score high in EI are rarely impulsive, have enhanced decision making processes, and better stress management. Taken together, this research suggests that our ability to understand and regulate our emotions are strengthened through in person communication.

\section{Social Competence}

Social competence is the ability to recognize the emotions of others by using personal skills to produce a desirable outcome (Kunnantt, 2004). Social competence overlaps with empathy in that they both involve an emotional understanding of other's feelings and emotions. To have social competence, one needs to have the ability of strong interpersonal skills such as, social awareness, self-regulation, and self-awareness (Kunnantt, 2004). In a study done by Kaypakli et al. (2020), they state that some adolescents face challenges in social situations and might prefer online social interactions because it is easier for them to show emotions through written words. If conflict arises, they would not have to work through and interpret other people's feelings through nonverbal communication. Munderia and Singh (2019) explain that individuals with deficit social skills may use a smartphone to maintain relationships in a virtual world with a sense of security and confidence in this online social interaction.

\section{Mindfulness}

Chang (2018) said mindfulness allows a person to understand and process their emotions, which allows them to interact with others more effectively. Favotto et al. (2017) reported in their research study on CMC on early adolescents (aged 11-15 years) that those who participated in CMC often felt absent from experiencing the moment. The researchers also noted that youth found technology useful for escaping reality when in an environment that was stressful (Favotto et al., 2017). Alhassan et al. (2018) states that they have no doubt that social relationships have been greatly impacted due to the introduction of technology, which was noted by older generations but there are gaps in the literature to show this relationship.

\section{Purpose of the Present Study}

After reviewing the literature, past research studies have examined specific age groups and the relationship between EI. However, there seems to be gaps where research studies have not addressed a combination of EI, mindfulness, and social competence among different age cohorts and whether there are differences in phone use. Thus, the present study examined the relationship among computer mediated communication, emotional intelligence, social competence, and mindfulness and whether or not there are differences in phone use among age groups. Our first hypothesis is that participants who score higher on Emotional Intelligence, Social Skills, and Mindfulness, will score lower on Problematic Phone Usage Scale. Our second hypothesis is that younger adults will score lower on Emotional Intelligence, Social Skills, and Mindfulness than young adults and middle aged. Finally, our third hypothesis is that younger adults will score higher on the Problematic Phone Usage Scale than young adults and middle aged.

\section{Methods}

\section{Participants}


In a small town in Southeast Georgia one hundred and eighty-seven participants completed an online survey from Qualtrics on phone use, social skills, and emotional intelligence. Of the 187 participants, 140 identified as female and 47 identified as male. Participants were grouped based on the age range. The first group was between the ages of 1830 years old and was categorized by "younger adult". There were 105 participants in this group. The second group was between the ages of 31-40 years old and was categorized by "young adults", and there were 30 participants in this group. The third group was between the ages of 41-50 and was categorized by "middle aged", and there were 30 participants in this group. Finally, the fourth group was 51 and older and was categorized by "older adults", there were 21 participants. Other demographic questions that were asked included ethnicity/ race, if they were married, widowed, divorced, or never married, and employment status.

\section{Design}

This study was both a correlational and ex-post facto design. For the ex-post facto analysis, the independent variable was age cohorts. Group one was categorized as "younger adult" with the age range from 18-30. Group two was categorized as "young adults" with the age range from 31-40. Group three was categorized as "middle aged" with the age range from 41-50. Group four was categorized as "older adults" with the age range from 51 and older. The dependent variables were Emotional Intelligence, mindfulness, social skills, and problematic phone usage. Participants who were between the ages of 18-25 were combined with participants who were 26-30 because of a lack of representation in the age range of 26-30. We also combined participants who were above the age of 65 with those who were between 51-64 because of a lack of representation in 65+. Combining age groups could be an extraneous variable that might have influenced the results between age and scores on emotional intelligence, mindfulness, social competence, and problematic phone usage. The current study was conducted during 2020 during an outbreak of COVID-19. This global pandemic could have also been an extraneous variable because of switching to online for work and/ or school. Thus, right before the debriefing statement, participants saw a question that asked if they thought their technology use increased during COVID-19. 154 out of 187 chose the answer "yes".

\section{Materials}

Computer Mediated Communication was operationally defined as the way that individuals communicate with each other via social media, texting, phone calls and Face Time. Computer Mediated Communication was measured using the Problematic Phone Usage Scale developed by Pamuk and Atli (2016). We modified the Problematic Phone Usage scale from 26 questions to 23 (Appendix F); this scale ranges from 1-4. Emotional Intelligence is the ability to regulate and manage one's emotions as well as interpreting other's emotions. EI was measured using the Trait Emotional Intelligence Questionnaire- Short Form (Cooper \& Petrides, 2010). This EI questionnaire was modified from 30 questions to 25 and ranges from 1-6 (Appendix C). Social skills are the way that individuals are able to communicate with each other in person. This includes striking up a conversation, making eye contact and being able to socialize. Social skills were measured using a 10 question Social Competence Scale that ranges from 1-4 and was developed by Sarason et al. (1985). Mindfulness is a way of being present and attentive in a given moment. Mindfulness was measured using the Kentucky Inventory of Mindfulness Skills. This scale was modified from 39 to 22 questions and ranges from 1-4 and was developed by Baer et al. (2004).

The participants completed an online survey from Qualtrics, consisting of scales such as Problematic Phone Usage Scale (PMPUS), Trait Emotional Intelligence Questionnaire- Short Form (TEIQ-SF), Social Competence Scale, and Kentucky Inventory of Mindfulness Skills. PMPUS was developed by Pamuk and Atli (2016) and has a high reliability of .85 . This scale was used to measure whether an individual spends a lot of time on their phone to the point it is too much and becomes a habit. PMPUS is a 23 question Likert-scale ranging from 1 (very inaccurate) to 4 (very accurate). With a high score meaning that the individual has a problem with phone use and a low score meaning there is not a problem. TEIQ-SF is a 25 question Likert-scale developed by Cooper and Petrides (2010), for psychometric measures see Cooper and Pretrides (2010). This scale ranges from 1 (completely disagree) to 6 (completely agree). With a high score meaning that an individual has a high EI and a low score meaning the individual has a low EI. Social 
Competence Scale was developed by Sarason et al. (1985) is a 10 question Likert-scale ranging from 1 (not at all like me) to 4 (a great deal like me). For psychometric measures see Sarason et al. (1985). A high score on this scale means that the individual has a high social competence. A low score on this scale means the individual has a low social competence. The Kentucky Inventory of Mindfulness Skills was developed by Baer et al. (2004) and is a 39 question Likert-scale ranging from 1 (very inaccurate) to 4 (very accurate). A high score meaning increase mindfulness and a low score meaning decrease mindfulness. We modified the scale to 22 questions (see Appendix D).

\section{Procedure}

The participants were recruited through email, social media, in person contact and also through Desire 2 Learn (D2L). Consent was given in accordance with the College of Coastal Georgia Institutional Review Board. The participants first read a consent form that states the purpose of the study, that they would be put at minimal risk and that all of their information would be kept confidential. Participants answered the Trait Emotional Intelligence Questionnaire- Short Form (TEIQ-SF), followed by Kentucky Inventory of Mindfulness Skills, Social Competence, and then answered the Problematic Phone Usage Scale. Before being presented with the debriefing statement, participants answered one question about the use of their technology before and during COVID-19. Finally, participants were presented with the debriefing form that stated the purpose of the study along with an email address that they can use if they have any questions.

\section{Results}

\section{Correlations}

To address our hypotheses, we ran a two-tailed Pearson correlational analyses among Emotional Intelligence, mindfulness, social competence, and problematic phone usage. As predicted, the Pearson correlational analyses showed that there was a negative correlation between Emotional Intelligence $(M=113.29, S D=13.67)$ and problematic phone usage $(M=45.90, S D=11.35), r(187)=-.315, p=.000$. There was a strong positive correlation between Emotional Intelligence $(M=113.29, S D=13.67)$ and mindfulness $(M=81.06, S D=8.62), r(187)=.707, p=.000$. There was a positive correlation between Emotional Intelligence $(M=113.29, S D=13.67)$ and social competence $(M=$ $34.77, S D=6.75), r(187)=.581, p=.000$. There was a negative correlation between problematic phone usage $(M=$ 45.90, $S D=11.35)$ and mindfulness $(M=81.06, S D=8.62), r(187)=-.416, p=.000$. There was a negative correlation between problematic phone usage $(M=45.90, S D=11.35)$ and social competence $(M=34.77, S D=6.75), r(187)=-$ $.234, p=.000$. There was also a positive correlation between mindfulness $(M=81.06, S D=8.62)$ and social competence $(M=34.77, S D=6.75), r(187)=.443, p=.000$.

Table 1. Correlations among the variables

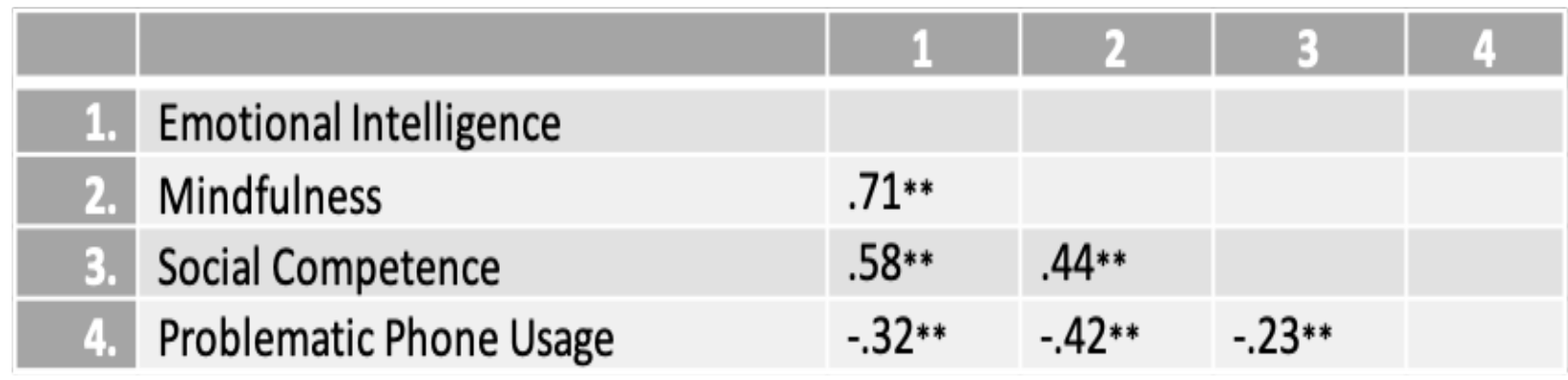

Note. $N=187 . * p<.05 ; * * p<.01$ 


\section{Journal of Student Research}

\section{One-way ANOVA}

A one-way between groups ANOVA was then conducted to compare each age cohort's level of problematic phone use and emotional intelligence, social skills, and mindfulness. There was a significant effect of Emotional Intelligence between the age cohorts $[F(3,183)=5.29, p=.002]$, as seen in Figure 1. One-way ANOVA descriptives indicated that the mean score for each group was- "younger adult" $(M=4.367, S D=0.66)$, "young adults" $(M=4.59, S D=0.58)$, "middle aged" $(M=4.76, S D=0.56)$, and "older adults" $(M=4.79, S D=0.51)$. Post hoc comparisons using the LSD test indicated the differences in Emotional Intelligence scores between younger adults and middle aged were statistically significant $(p=.002), F(3,183)$ and EI scores between younger adults and older adults were significant $(p=.005)$. There was no significant difference between the EI scores of younger adults and young adults $(p=.074)$ (Figure 1).

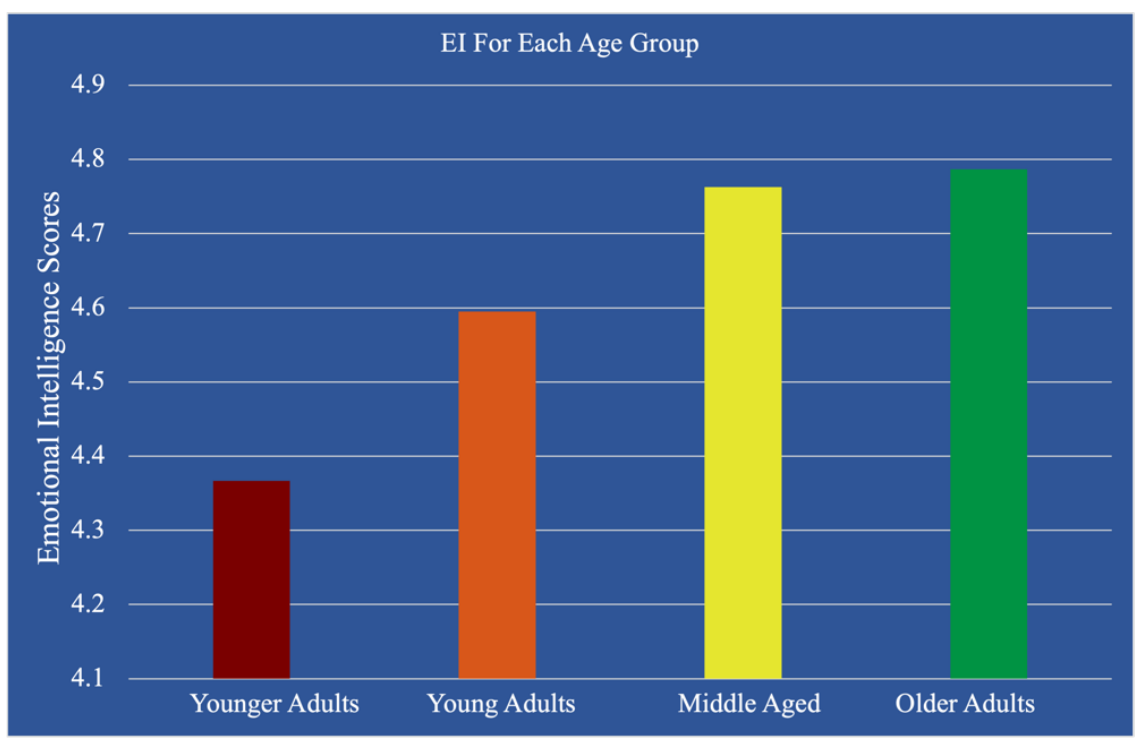

Figure 1. Emotional intelligence scores among cohorts.

There was a significant effect of mindfulness between age cohorts $[F(3,183)=5.15, p=.002]$, as seen in Figure 2. One-way ANOVA descriptive statistics indicated that the mean scores were as follows: for group one "younger adult" $(M=2.74, S D=0.44)$, group two "young adults" $(M=2.89, S D=0.42)$, group three "middle aged" $(M=3.01, S D=0.38)$, and group four "older adults" $(M=2.84, S D=0.43)$. Post hoc comparisons using LSD test indicated that the difference in mindfulness scores between younger adults and middle aged $(p=.002)$ and younger adults and older adults were statistically significant $(p=.006)$. However, mindfulness scores between younger adults and young adults were not statistically significant $(p=.077)$ (Figure 2 ). 


\section{Journal of Student Research}

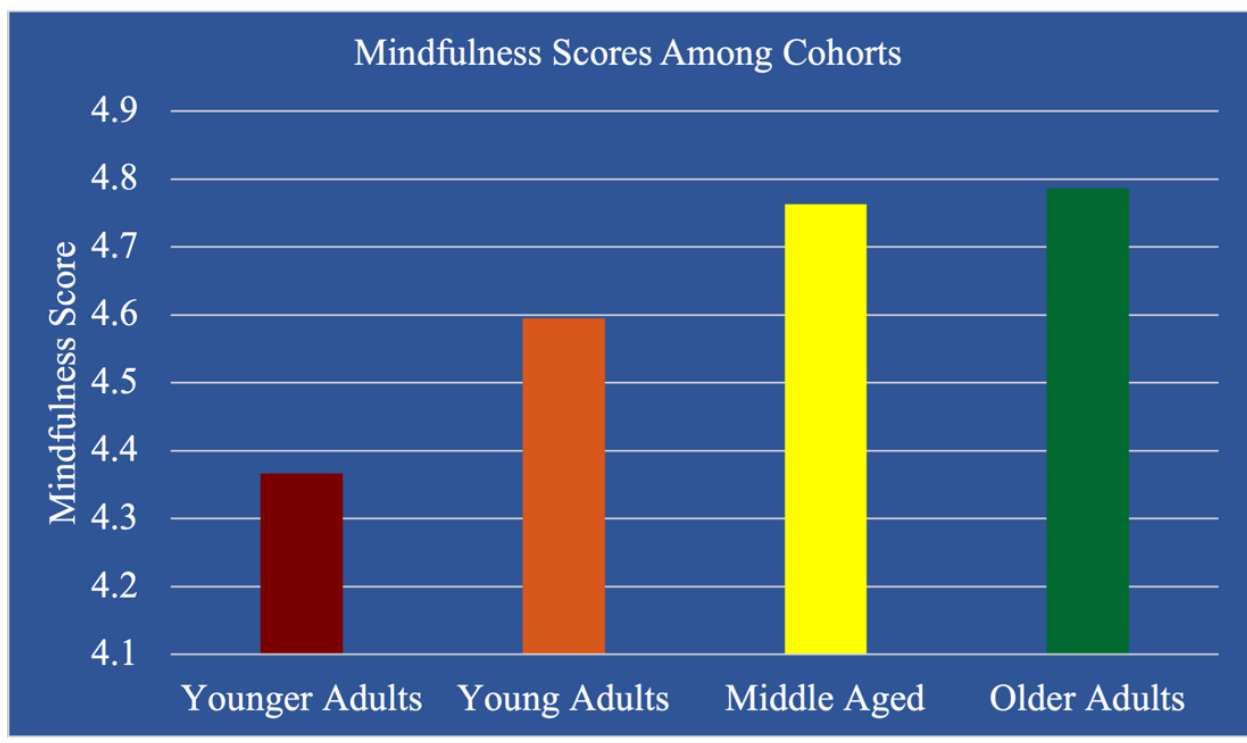

Figure 2. Mindfulness scores among cohorts.

There was a significant effect of problematic phone use between age cohorts $[F(3,183)=2.62, p=.052]$, as seen in Figure 3. One-way ANOVA descriptive statistics indicated that the mean score as follows: for group one "younger adult" $(M=2.08, S D=0.46)$, group two "young adults" $(M=1.96, S D=0.41)$, group three "middle aged" $(M=2.83, S D=0.53)$, and group four "older adults" $(M=1.93, S D=0.50)$. Post hoc comparisons using LSD test indicated that the differences in scores for problematic phone use between younger adult and older aged were statistically significant $(p=0.010)$. However, there were no differences between problematic phone use scores in younger adults relative to young adults $(p=0.197)$ and between younger adult compared to older adults $(p=0.183)$ (Figure 3).

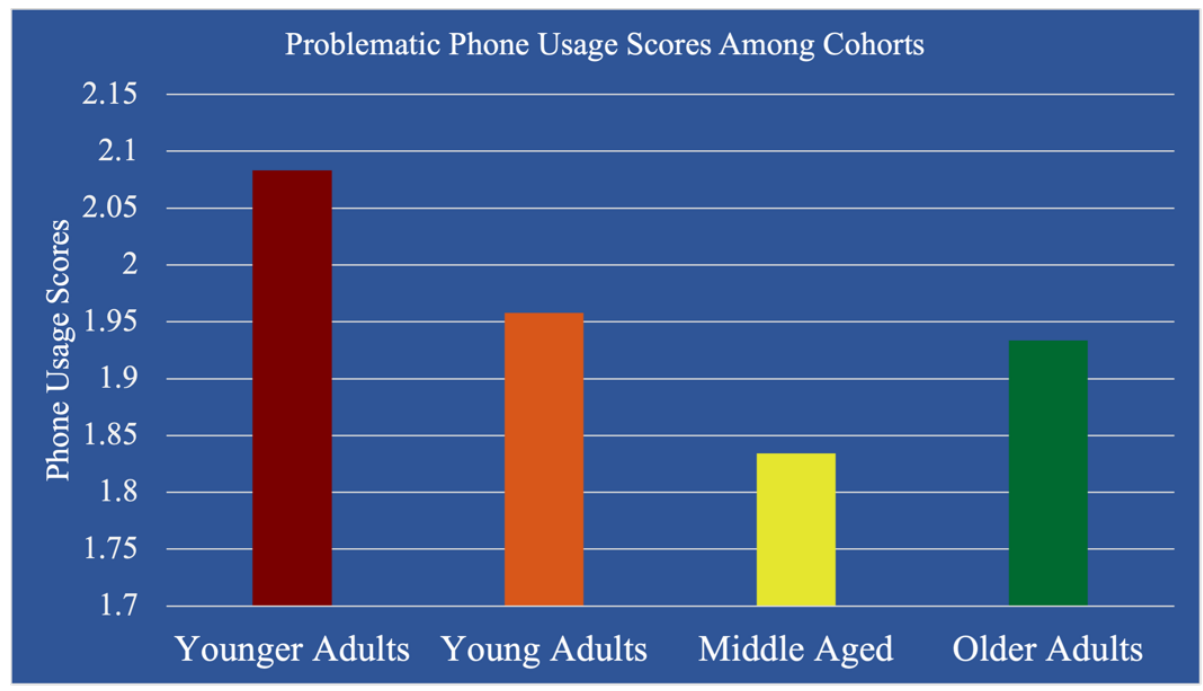

Figure 3. Problematic phone usage among cohorts.

There was not a significant effect of social competence among age cohorts $[F(3,183)=2.10, p=.102]$, as seen in Figure 4. One-way ANOVA descriptive statistics indicated that the mean scores were as follows: for group one "younger adult" was $(M=2.51, S D=0.71)$, group two "young adults" $(M=2.67, S D=0.85)$, group three "middle aged" $(M=2.81, S D=0.70)$, and group four "older adults" $(M=2.82, S D=0.73)$. LSD test indicated that social 


\section{Journal of Student Research}

competence scores differences between younger adult and middle aged were statistically significant $(p=.045)$. However, there was no difference in social competence scores between younger adult and young adults $(p=0.27)$ and scores between younger adult and older adults $(p=0.074)$.

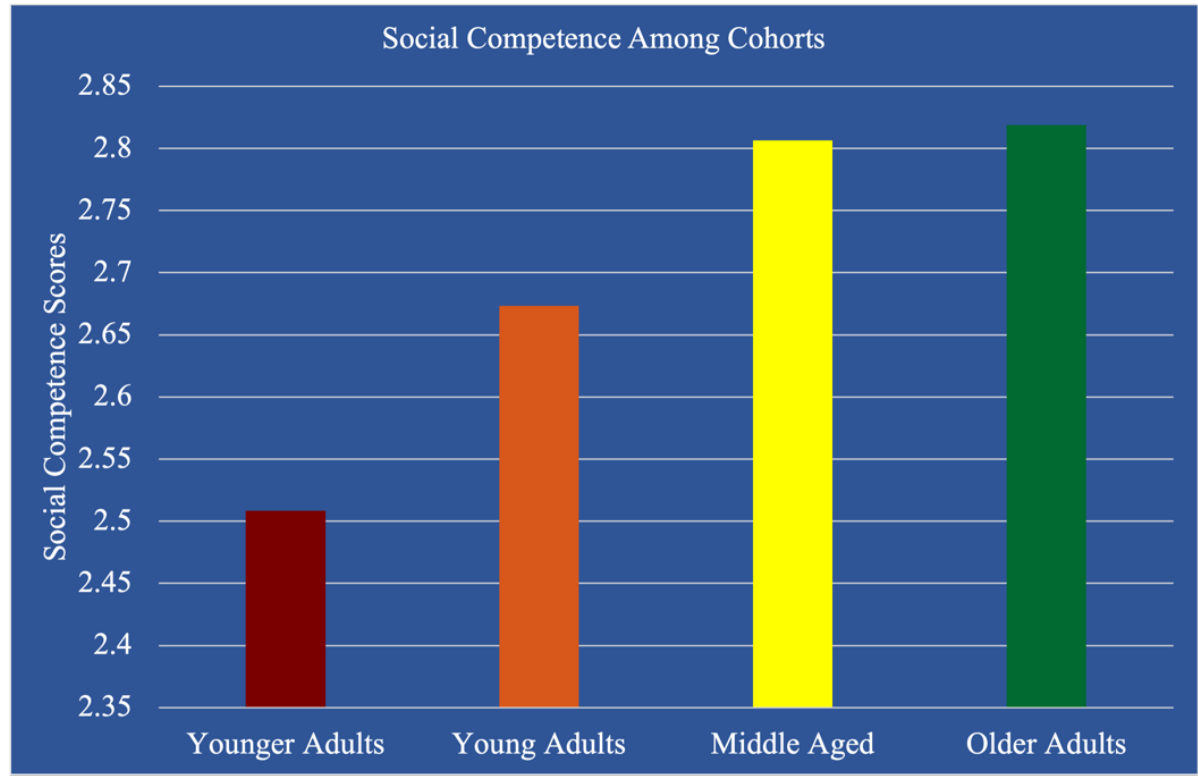

Figure 4. Social competence among cohorts.

\section{Discussion}

The purpose of the current study was to examine the relationship among computer mediated communication, emotional intelligence, social competence, and mindfulness and whether or not there are differences in phone use among age groups. Our first hypothesis stated that participants who score higher on Emotional Intelligence, Mindfulness, and Social Competence, would score lower on Problematic Phone Usage. This hypothesis was partially supported; indeed, higher EI, mindfulness, and social competence was related to lower problematic phone use. This was significant between younger adults, middle aged and older adults but not between young adults and other cohorts. Through our research we were able to partially support the statement by Sural et al. (2019) which indicates that lower emotional intelligence may be associated to having a higher problematic excessive use of technology. We found a negative correlation between Emotional Intelligence and problematic phone usage where as EI increased, problematic phone use decreased. Arrivillaga et al. (2020)'s research study on adolescents with problematic phone use, stated that those who had a lower smartphone use, had a higher emotional intelligence. The current study expands these findings and can be applied to older generations that have a lower problematic phone use, have a higher Emotional Intelligence but also are higher in mindfulness and social competence.

Our second hypothesis was that younger adults would score lower on Emotional Intelligence, Social Skills and Mindfulness than middle aged and older adults. This hypothesis was supported; we saw that scores from younger adults were much lower than middle aged and older adults.

Finally, our third hypothesis was that younger adults would score higher on Problematic Phone Usage than middle aged and older adults. This hypothesis was partially supported in that younger adults had a significantly larger problematic phone use than middle aged. But there was not a significance between younger adults, young adults, and older adults. This hypothesis was supported by Bianchi and Phillips (2005)'s, survey on problematic phone usage 
among young adults. They found that younger adults had a higher phone use problem than any other age group. The current study showed that younger adults had a greater impulse towards their smartphones than the older generation.

\section{Implications}

In the present study, we wanted to see if technology negatively impacts the development of social skills and the ability to regulate emotions. Our focus was to examine whether the four variables mentioned impact the younger generation more than the older generation and indeed they did. However, while not statistically significant, we saw a spike in the older adult age cohort having a higher problematic phone use score than middle aged. While we do not know what brought on this spike, it is worth exploring further. We believe it is important to investigate the social impact of smart phones among different cohorts, especially the younger generation who might lack the ability to process and regulate their emotions as their frontal lobe is not fully developed (Giedd et al., 1999). It is important to closely watch the development of technology and how it enhances our lives but also impacts our wellbeing. Research has shown that technology impacts our wellbeing because of overstimulation that can lead to anxiety, depression, and loneliness (Alhassan et al., 2018; Bian and Leung, 2015; Gao et al., 2016; Scott et al., 2016). If the younger generation is not capable of processing their emotions in the same ways as adults, depression and anxiety may have a greater effect on their overall wellbeing.

\section{Conclusion}

In conclusion, our study was able to support previous research that has been done while also expanding on the emotional and social impacts of technology among age groups. Results of this study point to the idea that excessive phone use impacts our overall well-being, with younger adults experiencing a greater effect. A society with a low wellbeing may experience anxiety, depression, decrease motivation, lack of empathy, or decreased social skills (Alhassan et al., 2018; Bian and Leung, 2015; Gao et al., 2016; Scott et al., 2016). They may have difficulty engaging in everyday activities as well as lose interest in participating in society.

\section{Limitations}

Limitations that we had in the current study included the fact that it was ran during a global pandemic where all schools were switched to online. This switch to online resulted in people using technology more than they normally would have. Promoting this survey and recruitment of participants was also a limitation due to social distancing during the COVID-19 pandemic. The pandemic forced us to use an online only format for recruitment and distribution of the survey. We were unable to access classrooms, businesses, or populated areas to advertise our study. Due to the pandemic, this study cannot be generalized to normal conditions. In the future we would like to compare these results to when the pandemic is over. Another limitation was the small sample size as well as sample bias. This study was conducted in a small town in Southeastern Georgia and our total sample size was 187; therefore, this study cannot be applied on a national or international level. Of the 187, 140 identified as female and 47 identified as male. Groups were divided based on age cohort with 105 younger adults, 30 young adults, 30 middle aged, and 22 older adults. The unequal group number distribution could have skewed some of the results; therefore, sample size should be increased in each age cohort for more representation in future research. Additionally, future researchers should include children under 18 and examine their problematic phone use to compare against other cohorts. 


\section{Journal of Student Research}

\section{Acknowledgments}

We would like to thank Dr. Jennifer Gray for taking time to review our manuscript and provide knowledgeable input. We appreciate Dr. Brian Pope's assistance with SPSS data entry and interpreting results. We would like to show our gratitude to the College of Coastal Georgia for providing online resources and databases that made running this research possible. We would also like to thank the participants for taking the time out of their day to participate in our study.

\section{References}

Alhassan, A. A., Alqadhib, E. M., \& Taha, N. W., Alahmari, R. A., Salam, M. \& Almutairi, A. F. (2018). The relationship between addiction to smartphone usage and depression among adults: A cross sectional study. BMC Psychiatry, 18(148), 1-8. doi: 10.1186/s12888-018-1745-4

Arrivillaga, C., Rey, L., \& Extremera, N. (2020). Adolescents' problematic internet and smartphone use is related to suicide ideation: Does emotional intelligence make a difference? Computers in Human Behavior, 110. https://doi.org/10.1016/j.chb.2020.106375

Baer, R. A., Smith, G. T., \& Allen, K.B (2004). Assessment of mindfulness by self-report. Assessment, 11(3), 191206. doi:10.1177/1073191104268029

Bian M, \& Leung, L. (2015). Linking loneliness, shyness, smartphone addiction symptoms, and patterns of smartphone use to social capital. Social Science Computer Review, 33(1), 61- 79. doi: 10.1177/0894439314528779

Bianchi, A. \& Phillips, J. (2005). Psychological predictors of problem mobile phone use. Cyber Psychology \& Behavior, 8(1), 39-51. doi:10.1089/cpb.2005.8.39

Chang, L. (2018). Adult attachment in close relationships and trait emotional intelligence: The moderating role of mindfulness. Dissertation, 501.

https://digscholarship.unco.edu/cgi/viewcontent.cgi? article=1488\&context=dissertations

Cooper, A., \&Petrides, K. V. (2010). A psychometric analysis of the trait emotional intelligence questionnaire short form (TEIQue-SF) using item response theory. Journal of Personality Assessment, 92(5), 449-457. doi: $10.1080 / 0022389.2010 .497426$

Favotto, L., Michaelson, V., \& Davison, C. (2017). Perceptions of the influence of computer mediated communication on the health and well-being of early adolescents. International Journal of Qualitive Studies on Health and Well-Being, 12. doi:10.1080/17482631.2017.1335575

Gao, Y., Li, A., Zhu, T., Liu, X., \& Liu, X. (2016). How smartphone usage correlates with social anxiety and loneliness. National Library of Medicine. doi:10.7717/peerj.2197

Giedd, J., Blumenthal, J., Jeffries, N., Castellanos, F., Liu, H., Zijdenbos, A., Paus, T., Evan, A., \& Rapoport, J. (1999). Brain development during childhood and adolescence: a longitudinal MRI study. Nature Neuroscience, 2(10), 861-863 
Harris B, Regan T, Schueler J, Fields SA. (2020). Problematic Mobile Phone and Smartphone Use Scales: A Systematic Review. Frontiers in Psychology, 11:672. doi:10.3389/fpsyg.2020.00672

Kaiser, E. (2018). The association between smartphone use and emotional intelligence on romantic relationship satisfaction among young adults. Theses and Dissertations Family Sciences, 62, 1-46.

Kaiser Family Foundation. (2010). Generation M2: Media in the lives of 8- to 18- year- olds. https://www.kff.org/wp-content/uploads/2013/04/8010.pdf

Kaypakli, G., Metin, O., Varmis, D., Ray, P., Celik, G., Karci, C., Tahiroglu, A. (2020). Technological addictions in attention deficit hyperactivity disorder: Are they associated with emotional intelligence? Indian Journal of Psychiatry, 62(6). doi:10.4103/psychiatry.IndianJPsychiatry_369_19

Kunnanatt, J. (2004). Emotional Intelligence: The new science of interpersonal effectiveness. Human Resource Development Quarterly, 15(4), 489-495.

Mayer, J., Salovey, P., \& Caruso, D. (2008). Emotional intelligence, new ability or eclectic traits? American Psychologist,63(6),503-517. https://scholars.unh.edu/cgi/viewcontent.cgi?article=1353\&context=psych facpub

Munderia, R., \& Singh, R. (2019). The relationship between social skills and perceived smartphone usage. Journal of Psychosocial Research, 14(1), 201-210.

Pamuk, M., \& Atli, A. (2016). Development of problematic phone usage scale for university students: validity and reliability study.Dusunen Adam: The Journal of Psychiatry and Neurological Sciences, 49-59. doi:10.5350/dajpn2016290105

Pew Research Center (2019). mobile fact sheet. Internet \& Technology. https://www.pewresearch.org/internet/factsheet/mobile/

Sarason, B. R., Sarason, I. G., Hacker, T. A., \& Basham, R. B. (1985). Concomitants of social support: Social skills, physical attractiveness, and gender. Journal of Personality and Social Psychology, 49(2), 469-480.

Scott, D. A., Valley, B., \& Simecka, B. A. (2016). Mental health concerns in the digital age. Int J Mental Health Addiction, 15, 604-613.

Sural, I., Griffiths, M.D., Kircaburun, K. \& Emirtekin, E. (2019). Trait emotional intelligence and problematic social media use among adults: The mediating role of social media use motives. International Journal of Mental Health and Addiction, 17(2), 336-345. doi:10.1007/s11469-018-0022-6 